\title{
Protective Effects of Millettia Pulchra Flavonoids on Myocardial Ischemia In Vitro and In Vivo
}

\author{
Jianchun Huang ${ }^{\mathrm{a}}$ Xudong Zhangab Feizhang Qin ${ }^{\mathrm{a}} \quad$ Yingxin Li $^{\mathrm{a}} \quad$ Xiaoqun Duan ${ }^{\mathrm{a}}$ \\ Jie Jian ${ }^{\mathrm{a}}$ Yongwen $\mathrm{Li}^{\mathrm{a}}$ Jian Chen ${ }^{\mathrm{a}}$ Renbin Huang ${ }^{\mathrm{a}}$
}

aDepartment of Pharmacology, Guangxi Medical University, Nanning, bMuDanJiang Medical University, MuDanJiang, PR China

\section{Key Words}

Millettia pulchra flavonoids • Myocardial ischemia • Apoptosis • Cardiac hemodynamics

\begin{abstract}
Background: Previous studies have demonstrated that Millettia pulchra flavonoids (MPF) exhibit protective effects on myocardial ischemia reperfusion injury (MI/RI) in isolated rat hearts and show anti-oxidative, anti-hypoxic and anti-stress properties. Methods: In this study, the cardioprotective effects of MPF on myocardial ischemia and its underlying mechanisms were investigated by a hypoxia/ reoxygenation $(\mathrm{H} / \mathrm{R})$ injury model in vitro and a rat MI/RI model in vivo. Results: We found that the lactate dehydrogenase (LDH) and inducible nitric oxide synthase (iNOS) activities were decreased in the MPF pretreatment group, whereas the activities of constructional nitric oxide synthase (cNOS), total nitric oxide synthase (tNOS), $\mathrm{Na}^{+}-\mathrm{K}^{+}$-ATPase and $\mathrm{Ca}^{2+}-\mathrm{Mg}^{2+}$-ATPase were significantly increased. In addition, the cardiocytes were denser in the MPF groups than in the control group. The mortality rate and apoptosis rate of cardiocytes were significantly decreased. Furthermore, pretreatment with MPF in vivo significantly improved the hemodynamics, decreased malondialdehyde (MDA) abundance, increased the activities of plasma superoxide dismutase (SOD) and glutathione peroxidase (GSH-Px) and decreased the expression of the Bax protein and ratio Bax/Bc1-2 ration. Conclusions: These results suggest that MPF is an attractive protective substance in myocardial ischemia due to its negative effects on heart rate and ionotropy, reduction of myocardial oxidative damage and modulation of gene expression associated with apoptosis.
\end{abstract}




\section{Introduction}

Ischemic heart disease is a leading cause of morbidity and mortality worldwide. Myocardial ischemia reperfusion injury (MI/RI) can result in arrhythmia, cardiocyte apoptosis, heart hypofunction and other disorders $[1,2]$. The pathophysiology mechanisms behind MI/RI are related to many factors, such as myocardial tissue dysfunction, massive free radical production, changes in hemorheology, increased inflammation, and platelet activation [3, 4]. A substantial amount of evidence from animal experiments and clinical studies supports the idea that reactive oxygen species play a critical role in MI/RI and are a target for therapeutic interventions [5]. Oxygen-derived free radicals and other reactive species are key factors that lead to the oxidative damage of membrane lipids, proteins and carbohydrates, resulting in various alterations of the myocardium, including effects on antioxidant synthesis, inflammation and apoptosis [6-8].

Pharmacological preconditioning is a cardioprotective mechanism induced by drugs or chemicals that can trigger the release of some endogenous protective substances. It is well known that preconditioning by some opioids [9] or potassium channel openers [10] demonstrates protective effects against MI/RI. Recently, increased attention has been focused on traditional Chinese herbal treatments due to their unique decrease of oxidative stress efficacy and limited adverse reactions. For example, flavonoid compounds, which are widely expressed in plants, have important roles in physiological functions. Previous studies have indicated that preconditioning by some flavonoid compounds exhibits cardioprotection against MI/RI [11-13]. Millettia pulchra (Benth.) Kurz var. Laxior (Dunn) Z.Wei (MKL) is a traditional Chinese medicinal herb that is widely distributed in the Guangxi Province of China $[14,15]$. Previous studies have demonstrated that extracts of its roots demonstrate antihypertensive, anti-oxidative and anti-inflammatory effects [16]. Millettia pulchra flavonoids (MPF) is the major effective ingredient in the MKL root extract [17]. Previous studies have demonstrated that MPF exhibits protective effects on myocardial ischemia reperfusion injury in isolated rat hearts and shows hydroxyl radical and oxyradical scavenging, antihypoxic and anti-stress properties [18-20]. Given this information, we hypothesized that anti-oxidative activities may also be involved in the effect of MPF on myocardial ischemia. The objective of the present study was to determine the anti-apoptosis and anti-myocardial ischemic effects of MPF and to further characterize their mechanisms.

\section{Materials and Methods}

\section{Animals}

Male and female SD rats weighing 250-280 g and 1-3 d SD neonate rats, SPF, were provided by the Experimental Animal Center of Guangxi Medical University (Guangxi, China). The studies were performed according to the protocols approved by our institutional ethics committee. All rats were housed under controlled conditions at a temperature of $25 \pm 2{ }^{\circ} \mathrm{C}$ and a relative humidity of $60 \pm 10 \%$, with room air changes 12-18 times/hr and a 12-hr light/dark cycle. Food and water were provided ad libitum.

\section{Reagents}

The verapamil injection was obtained from Hefeng Pharmaceutical Co., Ltd. (Shanghai, China); Dilthiazem (DIL) tablets were obtained from Shanghai Sine Wanxiang Pharmaceutical Co., Ltd. (Shanghai, China); Dulbecco's modified Eagle's medium ( DMEM), fetal bovine serum (FBS) and trypsin were purchased from Gibco. (USA); The VFITC/PI apoptosis kit was purchased from Biovision. (USA); Mouse antibodies against Bcl-2 and Bax and corresponding immunohistochemistry reagents were purchased from Santa Cruz Biotechnology. (USA); lactate dehydrogenase (LDH), nitric oxide synthase (NOS), malondialdehyde (MDA), superoxide dismutase (SOD), glutathione peroxidase (GSH-Px) and Coomassie (Bradford) protein assay kits were acquired from Nanjing Jiancheng Bioengineering Research Institute (Nanjing, China). 
Huang et al.: Protective Effects of MPF on Myocardial Ischemia

Table 1. Groupings and treatment. aThe H/R model was induced, except for the blank group. All values represent the final concentration. ${ }^{\mathrm{b}} \mathrm{The} \mathrm{MI} /$ RI model was established by left anterior descending (LAD), except for the sham group

\begin{tabular}{lll}
\hline Group & aIn vitro (n=8 plates) & bIn vivo (n=8) \\
\hline Blank (Sham) control & blank serum & $2 \mathrm{ml} / \mathrm{kg} \mathrm{NS}$ \\
Model control & blank serum & $2 \mathrm{ml} / \mathrm{kg} \mathrm{NS}$ \\
Positive control & verapamil $10 \mathrm{mg} / / \mathrm{L}$ & $\mathrm{DIL} 5 \mathrm{mg} / \mathrm{kg}$ \\
Low dose of MPF & $6 \mathrm{mg} / / \mathrm{L}$ & $20 \mathrm{mg} / \mathrm{kg}$ \\
Medium dose of MPF & $12 \mathrm{mg} / / \mathrm{L}$ & $40 \mathrm{mg} / \mathrm{kg}$ \\
High dose of MPF & $24 \mathrm{mg} / / \mathrm{L}$ & $80 \mathrm{mg} / \mathrm{kg}$ \\
\hline
\end{tabular}

Drugs and pharmacological serum preparation

MPF was isolated from the root of MKL as previously described [16] and diluted with 0.5\% DMSO at the appropriate concentrations as needed. The MPF medicated serum was prepared at a concentration of $24 \mathrm{mg} / \mathrm{L}$, and the verapamil medicated serum was prepared at a concentration of $10 \mathrm{mg} / \mathrm{L}$, as previously described, with few modifications. Briefly, MPF and Verapamil were injected into the rat duodenum one hour after the instillation; blood was drawn under aseptic conditions, and the serum was separated. After 30 minutes of inactivation at $56^{\circ} \mathrm{C}$, the serum was aliquoted and refrigerated separately from the blood.

\section{Cell culture and treatment}

The cardiomyocyte culture system was prepared as previously reported [21,22]. Briefly, the cells were dispensed into 24 -well plates at a density of $3 \times 10^{5}$ /well and grown in DMEM supplemented with $10 \%$ heattreated FBS, $100 \mathrm{U} / \mathrm{mL}$ penicillin, $100 \mathrm{U} / \mathrm{mL}$ streptomycin and $2 \mathrm{mmol} / \mathrm{L}$ glutamine in $5 \% \mathrm{CO}_{2}$ at $37{ }^{\circ} \mathrm{C}$. After 72-96 hours, the cells were randomly divided into 6 groups ( $n=8$ plates), as shown in Table 1 . The H/R injury model was established with hypoxia for 2 hours, followed by reoxygenation for 4 hours, in all groups except the blank control, as previously described [23]. The cells were incubated in a minimal amount of hypoxia medium and then placed into a hypoxia chamber. The chamber was subsequently flushed for 30 min with a $95 \% \mathrm{~N}_{2} / 5 \% \mathrm{CO}_{2}$ gas mixture, after which the cells in the chamber were returned to a $37{ }^{\circ} \mathrm{C}$ incubator for 2 hours. At the end of the hypoxic period, the chamber was removed from the incubator, and the hypoxic medium was rapidly replaced with oxygen-saturated medium. The $\mathrm{N}_{2}$ gas in the chamber was rapidly replaced with $\mathrm{O}_{2}$ gas, after which the cells in the chamber were returned to a $37{ }^{\circ} \mathrm{C}$ incubator for 4 hours. Two hours before the hypoxic treatment, the positive drug verapamil medicated serum $(10 \mathrm{mg} / \mathrm{L})$ or MPF medicated serum $(6,12,24 \mathrm{mg} / \mathrm{L})$ was added to the cell culture medium; the H/R model and blank control groups were treated with equal volumes of blank serum only.

\section{Experimental design}

Measurement of LDH activity and NOS in vitro. The culture medium was collected after H/R, and the $\mathrm{LDH}$, total nitric oxide synthase (tNOS), inducible nitric oxide synthase(iNOS) and constructional nitric oxide synthase (cNOS) activities were evaluated by ELISA according to the manufacturer's instructions.

Measurement of $\mathrm{Na}^{+}-\mathrm{K}^{+}$-ATPase and $\mathrm{Ca}^{2+}-\mathrm{Mg}^{2+}$-ATPase activities in vitro. After $\mathrm{H} / \mathrm{R}$, the cardiomyocytes were digested and centrifuged, and normal saline was added to the layer of cells to generate a cell suspension $\left(2 \times 10^{6} \sim 3 \times 10^{6}\right.$ cells $\left./ \mathrm{ml}\right)$. The activities of $\mathrm{Na}^{+}-\mathrm{K}^{+}$-ATPase and $\mathrm{Ca}^{2+}-\mathrm{Mg}^{2+}$-ATPase were evaluated by ELISA according to the manufacturer's instructions. The protein content was evaluated using the Coomassie brilliant blue method, and the activities were expressed as units per milligram of cardiomyocyte protein.

\section{Morphological changes and apoptosis of cardiocytes}

Morphological changes of the cardiocytes were detected using acridine orange staining after $\mathrm{H} / \mathrm{R}$ as previously described [24]. Briefly, the cardiocytes were harvested and fixed with 95\% alcohol for 15-30 min, treated for $30 \mathrm{~s}$ in $1 \%$ acetic acid, stained with $1 \times 10^{-4} \mathrm{mmol} / \mathrm{L}$ acridine orange for $30-60 \mathrm{~s}$, treated for $30 \mathrm{~s}-2$ min in $0.1 \mathrm{M} \mathrm{CaCl}_{2}$, washed three times with PBS and finally sealed using PBS. To measure the stained cells, four fields per well (100 cells per fields) were randomly selected to quantify the cells that had thick green-staining nuclei by using a fluorescence microscope. The percentages of thick green nuclei were analyzed, and the images were acquired using a digital camera system.

Detection of apoptosis using flow cytometry

Cardiocytes were harvested and washed three times with ice-cold PBS; the cells were stained with Annexin V-FITC and propidium iodide (PI) for $15 \mathrm{~min}$ at room temperature in $500 \mu \mathrm{L}$ binding buffer. Non- 
Huang et al.: Protective Effects of MPF on Myocardial Ischemia

stained cells were considered viable, and cells stained with Annexin V were determined to be in early-stage apoptosis. Surface exposure of phosphatidylserine in apoptotic cells was measured using the Annexin V-FITC apoptosis detection kit according to the manufacturer's instructions. The results were shown as cell histograms with four quadrants. Additional exposure to PI enabled the differentiation of early apoptotic cells (Annexin $\mathrm{V}+/ \mathrm{PI}-$, right lower quadrant) from late apoptotic cells (Annexin $\mathrm{V}+/ \mathrm{PI}+$, right upper quadrant). We also distinguished between normal cells (Annexin V-/PI-, left lower quadrant) and necrotic cells (Annexin V-/PI+, left upper quadrant).

\section{Rat MI/RI model and treatment}

The rats were randomly placed into 6 groups $(n=8)$ as shown in Table 1 . All animals were anesthetized with sodium pentobarbital $(60 \mathrm{mg} / \mathrm{kg}$, i.p.). The MI/RI model was established by ligation of the LAD for 30 $\mathrm{min}$, followed by reperfusion for $60 \mathrm{~min}$, as previously described [25]. The sham group was subjected to identical treatment without LAD artery ligation. During surgery, a subcutaneous electrode was inserted into the rat limb and continuously monitored by electrocardiograms (ECG) in the MI/RI model using the MS4000 biological signal recording and analysis system. The model was considered successfully established when the ST-segment was elevated during myocardial ischemia and decreased by at least $50 \%$ during reperfusion [26]. Thirty minutes prior to ligation, the positive drug DIL (5 mg/kg) or MPF $(20,40,80 \mathrm{mg} / \mathrm{kg} /$ day) was administered into the duodenum; the MI/RI model and sham control rats received equal volumes of saline only.

\section{Measurement of hemodynamic parameters}

During surgery, the MS 4000 system was used to record hemodynamic parameters including heart rate (HR), left ventricular systolic pressure (LVSP), left ventricular diastolic pressure (LVDP), left ventricular end-diastolic pressure (LVEDP), the largest upstroke velocity of the left ventricular pressure $\left(+\mathrm{dp} / \mathrm{dt}_{\text {max }}\right)$, the largest descendent velocity of the left ventricular pressure (-dp/dt ${ }_{\text {max }}$ ), the interval from beginning of left ventricular contraction to $+\mathrm{dp} / \mathrm{dt}_{\max }\left(\mathrm{t}-\mathrm{dp} / \mathrm{dt}_{\max }\right.$ ) at i0min (prior to ligation of the LAD), $\mathrm{i} 30 \mathrm{~min}$ (30 min after ligation), r30 min (30 min after reperfusion) and $\mathrm{r} 60 \mathrm{~min}$ (60 min after reperfusion) to evaluate cardiac function.

Estimations of SOD, GSH-Px and MDA in plasma

Blood was collected via the abdominal aorta and centrifuged, and the upper plasma layer was isolated to detect the SOD and GSH-Px activities and the MDA content. All of these factors were determined using commercially available kits according to the manufacturer's instructions.

\section{Detection of Bcl-2 and Bax expression}

The protein expression levels of Bcl-2 and Bax in myocardial tissues were detected using the appropriate immunohistochemical assay kit according to the manufacturer's instructions. Sample groupings and treatments were the same as previously described. Briefly, the sections were deparaffinized and microwaved twice for $10 \mathrm{~min}$ in $10 \mathrm{mM}$ sodium citrate ( $\mathrm{pH}$ 6.0). Sections were then incubated in endogenous peroxidase blocking solution for $10 \mathrm{~min}$ at room temperature followed by incubation with Bcl-2 and Bax monoclonal antibodies overnight at $4{ }^{\circ} \mathrm{C}$. After washing three times with PBS, the sections were incubated with biotinconjugated anti-rabbit secondary antibody for $10 \mathrm{~min}$. The sections were then washed three times with PBS, treated with streptavidin-peroxidase for $10 \mathrm{~min}$ and washed again with PBS three times. Finally, the specimens were incubated in diaminobenzidine for $5 \mathrm{~min}$, followed by hematoxylin counterstaining. Images from all sections were acquired using a digital camera system. Samples with a brown-stained cytoplasm and no blue-stained nuclei were considered Bcl-2- and Bax-positive cells, respectively. Four fields were randomly selected to quantify the positive cells using a high-power microscope $(\times 400)$. The data were expressed as the positive expression rate $\%=$ cells stained positive $/$ total cardiocytes $\times 100 \%$.

\section{Statistical analysis}

Each sample was assayed in triplicate. The results were averaged and expressed as the mean \pm SD. Oneway ANOVA followed by Bonferroni's multiple comparison test were used for statistical analysis. $P$-values less than 0.05 were considered statistically significant.

\section{KARGER}


Fig. 1. Effect of MPF on LDH activity after $\mathrm{H} / \mathrm{R}$ in cardiocytes in vitro. The results are presented as the mean $\pm \mathrm{SD}$ ( $\mathrm{n}=8$ ). ${ }^{\mathrm{a}} \mathrm{p}<0.05$ compared with blank control group, ${ }^{\mathrm{b}} \mathrm{p}<0.05$ compared with $\mathrm{H} / \mathrm{R}$ model group.

Fig. 2. Effect of MPF on NOS activity after $\mathrm{H} / \mathrm{R}$ in cardiocytes in vitro. The results are presented as the mean \pm SD ( $\mathrm{n}=8$ ). ${ }^{\mathrm{a}} \mathrm{p}<0.05$ compared with blank control group, ${ }^{b} \mathrm{p}<0.05$ compared with $\mathrm{H} / \mathrm{R}$ model group.
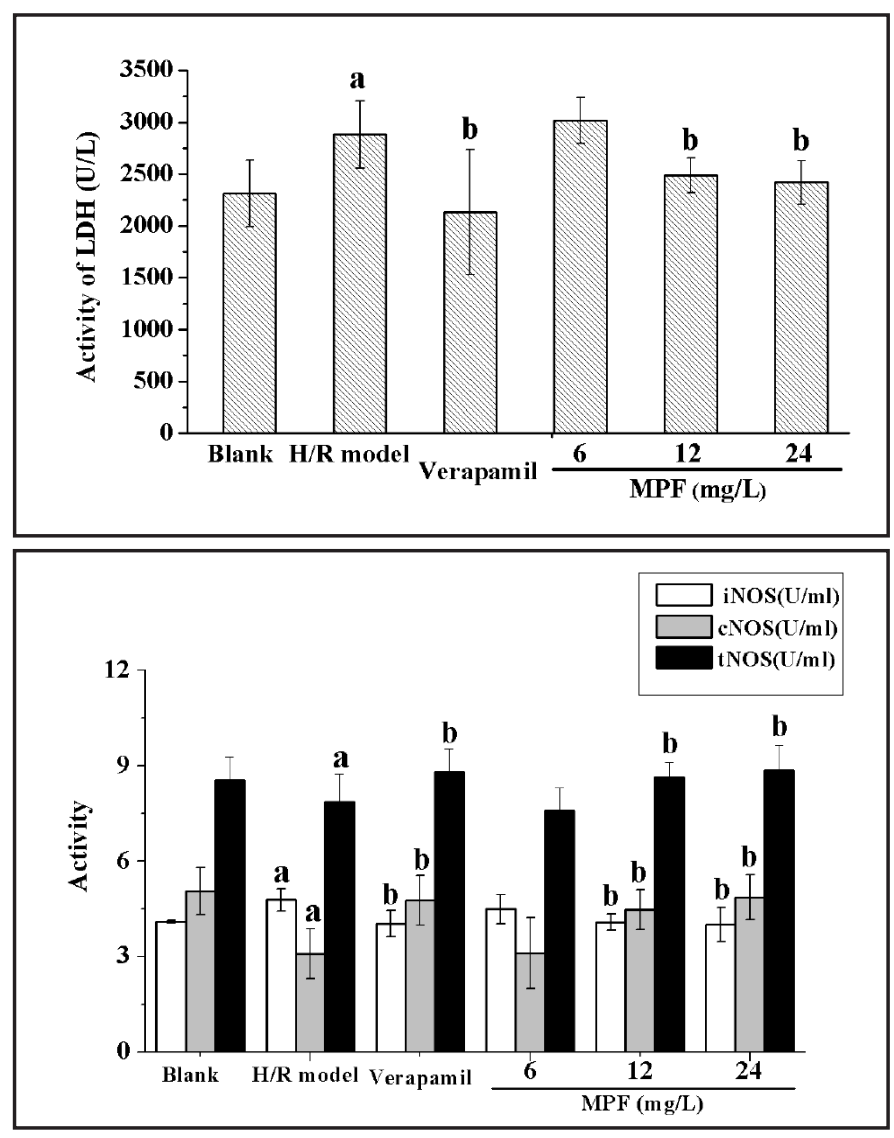

\section{Results}

\section{Effects of MPF on LDH and NOS activities in vitro}

Elevated LDH activity in the culture medium was detected in the H/R model group, and pretreatments with MPF $(12,24 \mathrm{mg} / \mathrm{L})$ and verapamil decreased the LDH activity $(P<0.05$, Fig. 1).

The iNOS activity in the culture medium increased, whereas the cNOS and tNOS activities were decreased in the H/R model group. In addition, pretreatment with MPF (12, $24 \mathrm{mg} / \mathrm{L})$ and verapamil increased the tNOS and cNOS activities $(P<0.05)$ while reducing the iNOS activity $(P<0.05)$ compared with the $\mathrm{H} / \mathrm{R}$ model group (Fig. 2$)$.

\section{Effects of MPF on $\mathrm{Na}+-\mathrm{K}+$-ATPase and $\mathrm{Ca}^{2+}-\mathrm{Mg}^{2+}$-ATPase in vitro}

The activities of $\mathrm{Na}^{+}-\mathrm{K}^{+}$-ATPase and $\mathrm{Ca}^{2+}-\mathrm{Mg}^{2+}$-ATPase were significantly decreased in the H/R model group compared with the activities detected in the blank control group $(P<0.05)$. In contrast, pretreatment with MPF $(12,24 \mathrm{mg} / \mathrm{L})$ and verapamil significantly increased the activities of $\mathrm{Na}^{+}-\mathrm{K}^{+}$-ATPase and $\mathrm{Ca}^{2+}-\mathrm{Mg}^{2+}$-ATPase (Fig. 3).

\section{Effects of MPF on morphological changes and cell apoptosis}

Cardiocyte cytoplasm was observed under red fluorescence, and the nuclei were visualized under green fluorescence after staining. Pretreatment with MPF (12, $24 \mathrm{mg} / \mathrm{L}$ ) and verapamil resulted in denser cardiocytes compared with the H/R model group that were less dense than the blank control group (Fig. 4). In addition, compared with the H/R model group, flow cytometric analysis showed that all dosages of MPF decreased the rate of apoptosis $(P<0.05)$ in a concentration-dependent manner (Fig. 5A-B). 
Fig. 3. Effects of MPF on $\mathrm{Na}^{+}-\mathrm{K}^{+}$-ATPase and $\mathrm{Ca}^{2+}-\mathrm{Mg}^{2+}-\mathrm{AT}-$ Pase activities after $H / R$ in cardiocytes in vitro. The results are presented as the mean \pm SD $(n=$ 8). ${ }^{\mathrm{a}} \mathrm{p}<0.05$ compared with blank control group, ${ }^{\mathrm{b}} \mathrm{p}<0.05$ compared with $H / R$ model group.

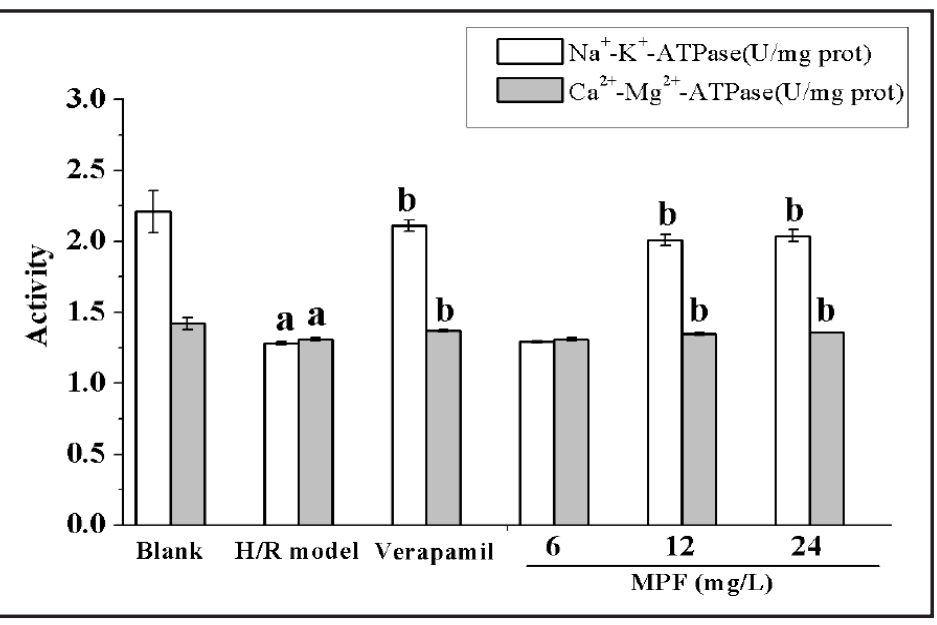

Fig. 4. Effects of MPF on the morphological changes and apoptosis of cardiocytes assessed by acridine orange stain after $\mathrm{H} / \mathrm{R}$ in vitro.
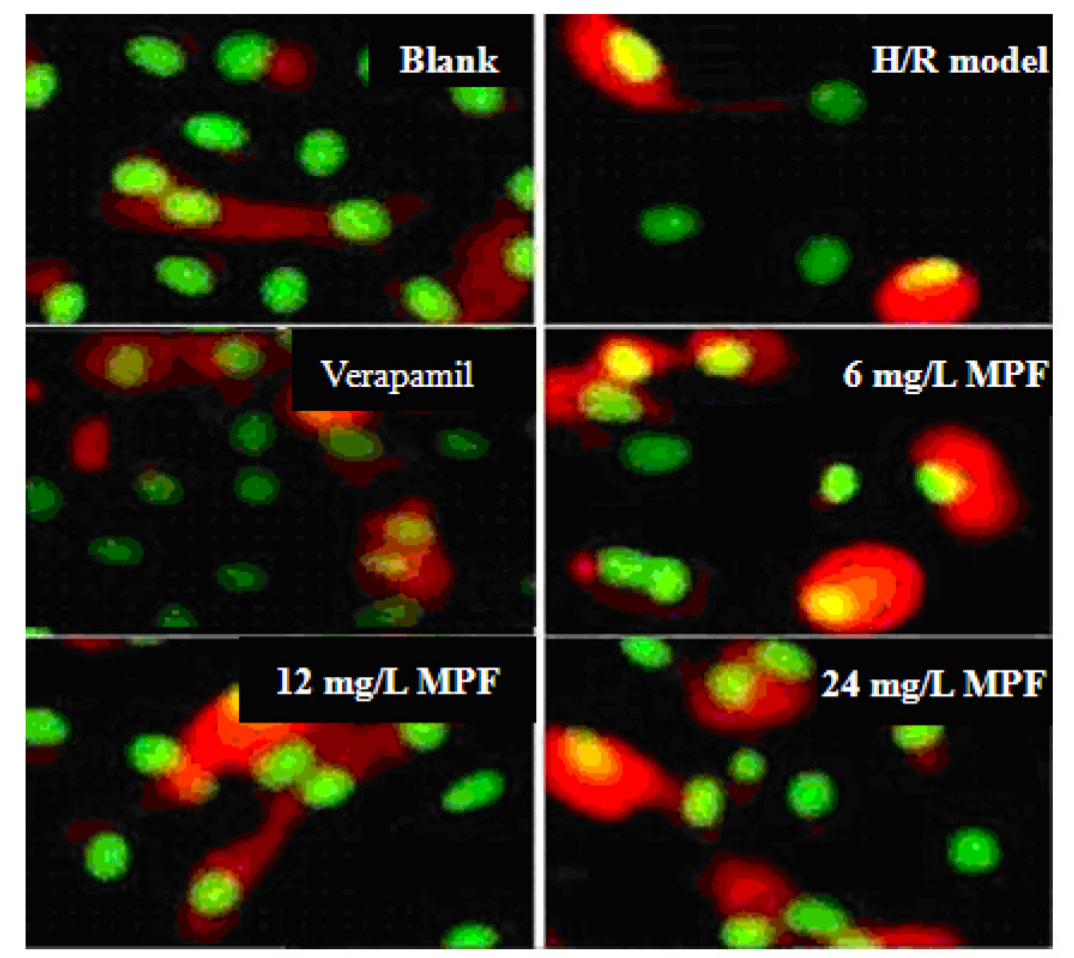

Effects of MPF on hemodynamic parameters

Compared with the MI/RI model group, pretreatment with MPF $(40,80 \mathrm{mg} / \mathrm{kg})$ and DIL increased HR, LVSP, $+\mathrm{dp} / \mathrm{dt}_{\text {max }}$ and $-\mathrm{dp} / \mathrm{dt}_{\text {max }}(P<0.05)$, whereas LVDP, LVEDP and $\mathrm{t}-\mathrm{dp} / \mathrm{dt}_{\text {max }}$ were significantly decreased $(P<0.05)$ (Fig. 6).

\section{Effects of MPF on SOD, GSH-Px and MDA in plasma}

A significant increase in serum MDA content and a decrease in SOD and GSH-Px activities were detected in the MI/RI model group. Compared with the MI/RI model group, pretreatment with MPF $(40,80 \mathrm{mg} / \mathrm{kg})$ increased the activities of SOD and GSH-Px $(P<0.05)$ and significantly decreased the MDA content in plasma $(P<0.05)$ (Fig. 7).

Effects of MPF on the expression of Bc1-2 and Bax proteins

Compared with the MI/RI model group, pretreatment with MPF showed no difference in Bc1-2 protein expression in either group $(P>0.05)$, but the expression of Bax and the ratio 
Fig. 5. Effect of MPF on cardiocyte apoptosis as detected by flow cytometry with AnnexV-FITC/ PI double staining after $\mathrm{H} / \mathrm{R}$ in vitro. Arrows indicate nonviable apoptotic cells.

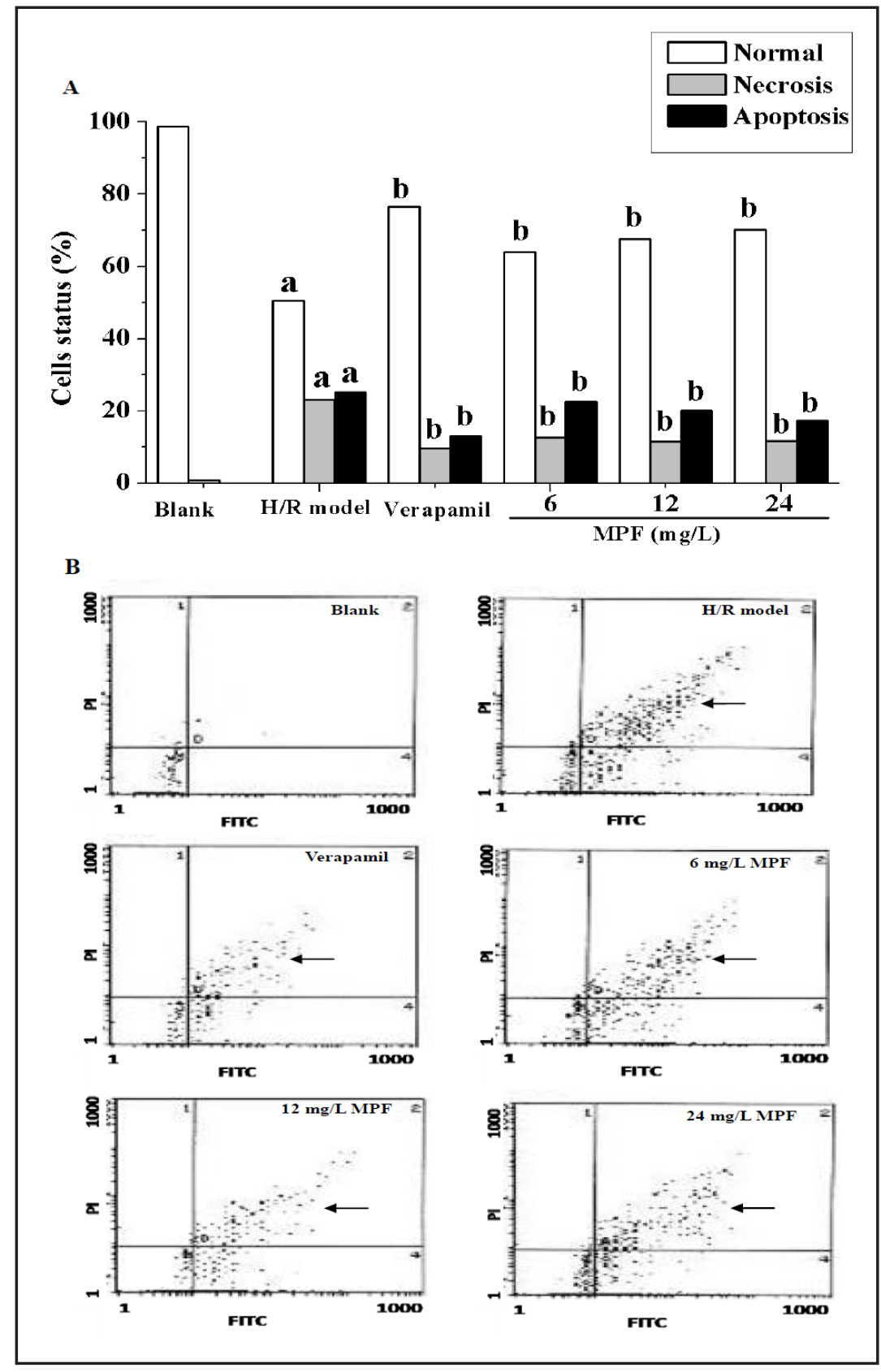

of Bax to Bc1-2 proteins were decreased significantly in the MPF $(40,80 \mathrm{mg} / \mathrm{kg}$ ) and DIL pretreatment groups $(P<0.05)$ (Fig. 8A-D).

\section{Discussion}

Several mechanisms might be involved in the MPF-mediated protective effects on myocardial ischemia injury. NO is an essential modulator of biological systems, including the cardiovascular system, and plays a critical role in cardioprotection. Additionally, cardioprotection is related to the levels of different types of NOS [27, 28]. It is widely accepted that iNOS induces apoptosis but that cNOS inhibits apoptosis [29-31]. In this study, we found that the iNOS activity was higher and the cNOS activity was lower in the H/R model group and that pretreatment with MPF could effectively reverse these changes. These results 


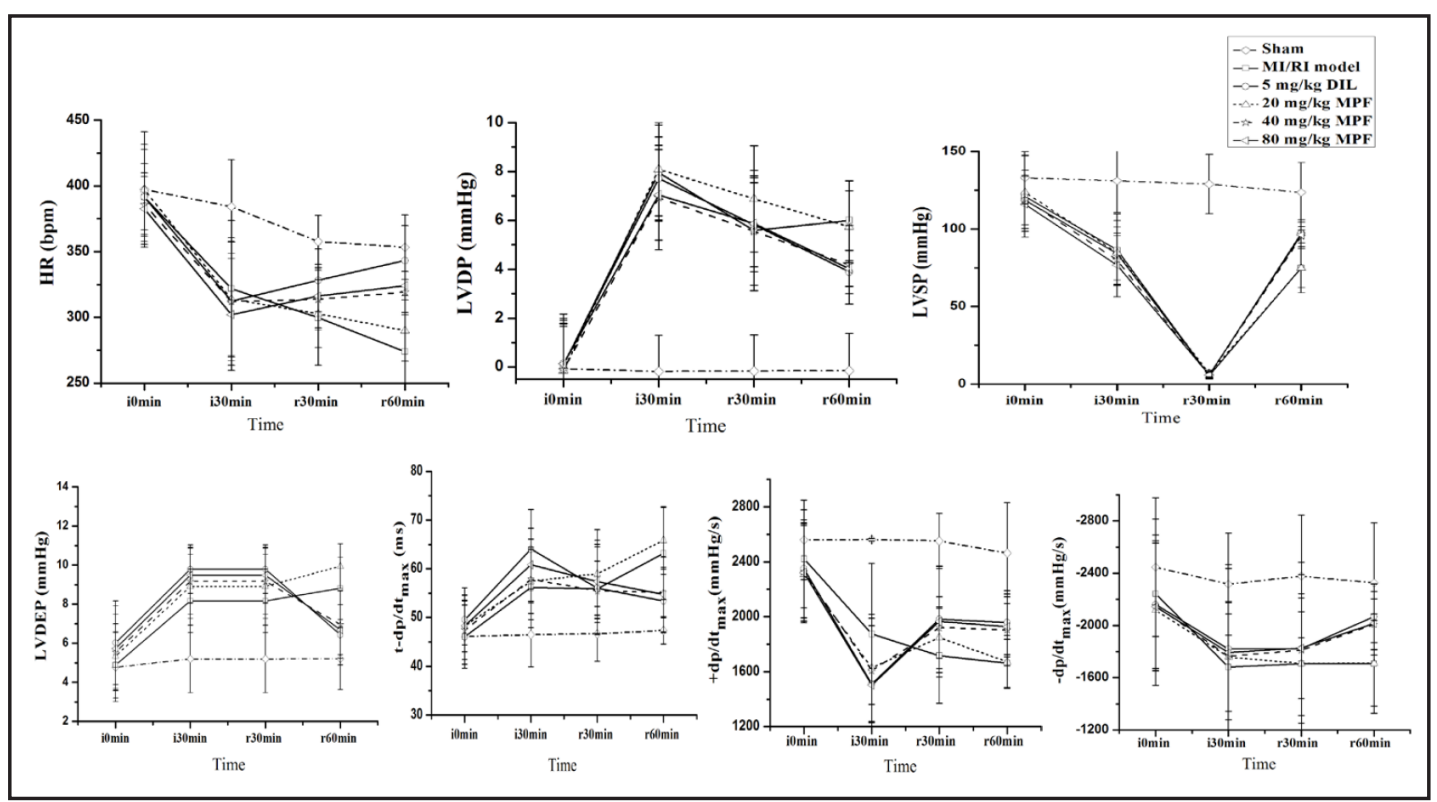

Fig. 6. Effects of MPF on hemodynamic parameters after MI/RI in rats. The results are presented as the mean $\pm \mathrm{SD}(\mathrm{n}=8)$.

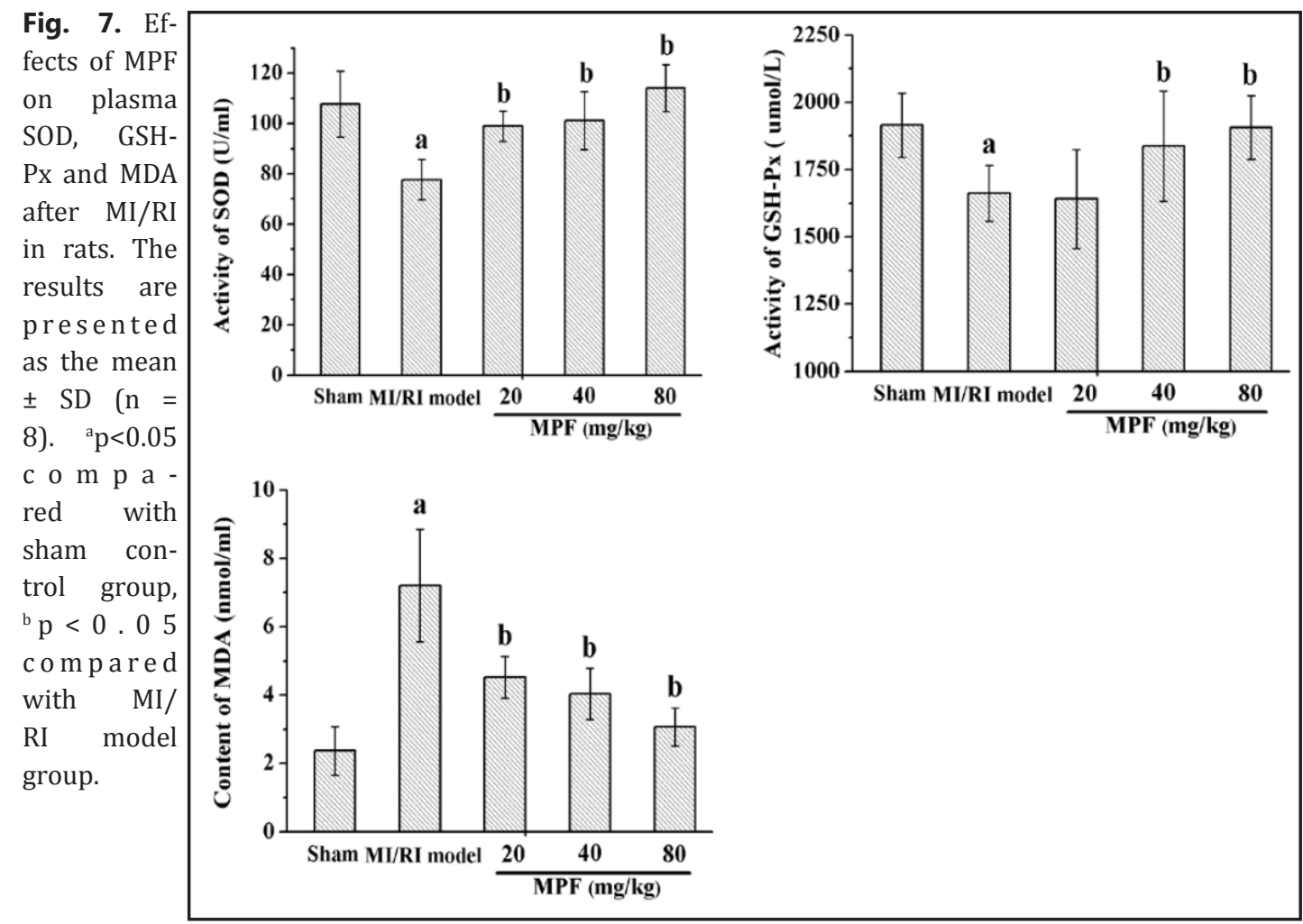

indicated that the anti-apoptotic and anti-ischemic effects of MPF were most likely related to the regulation of different NOS subtypes.

$\mathrm{LDH}$ is a cytosolic enzyme that is predominantly found in cardiac tissues. Variation in the serum LDH isoenzyme pattern is considered a definitive diagnostic criterion for the assessment of myocardial damage because the rate of LDH appearance and disappearance in the blood indicates the size of the infarction [31]. In the present study, LDH activity was increased in the H/R model group compared with the blank control group, which is supported 
$\mathbf{A}$

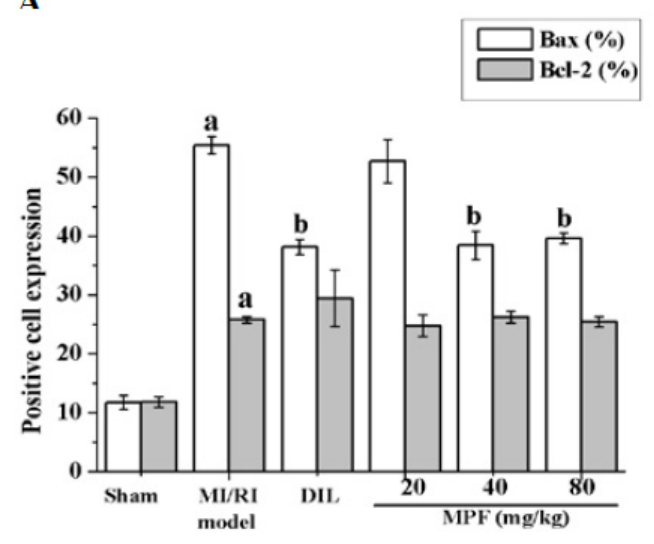

$\mathrm{C}$
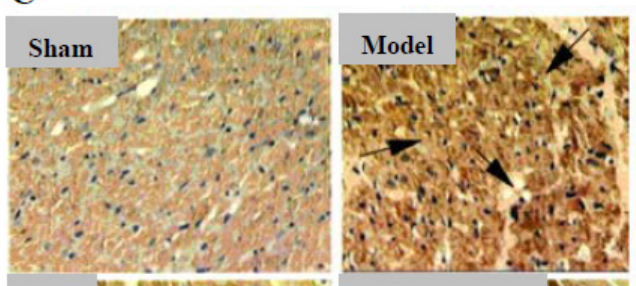
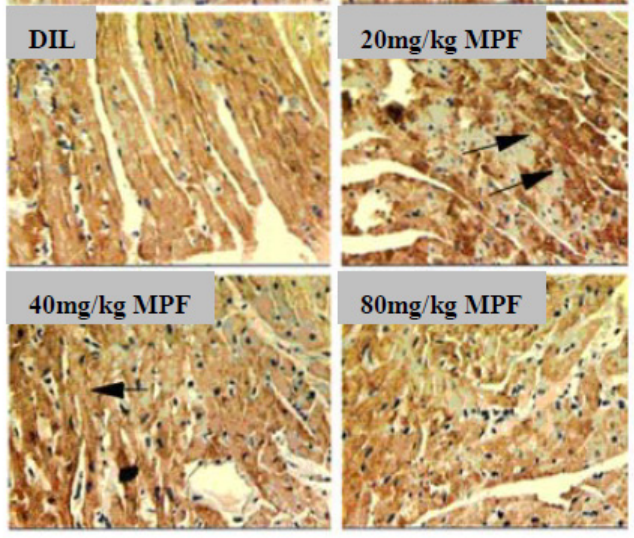

B

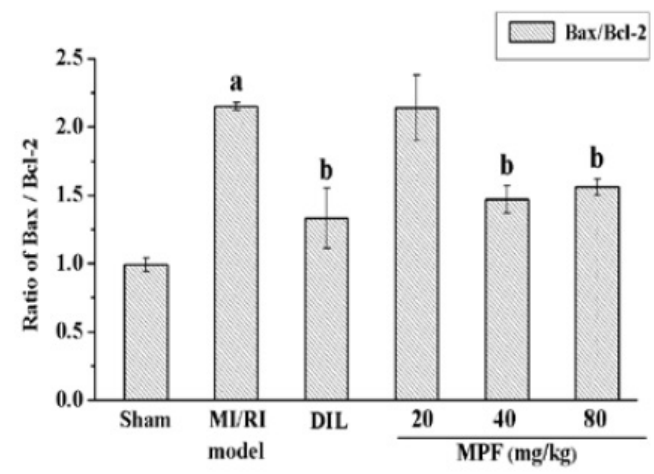

D
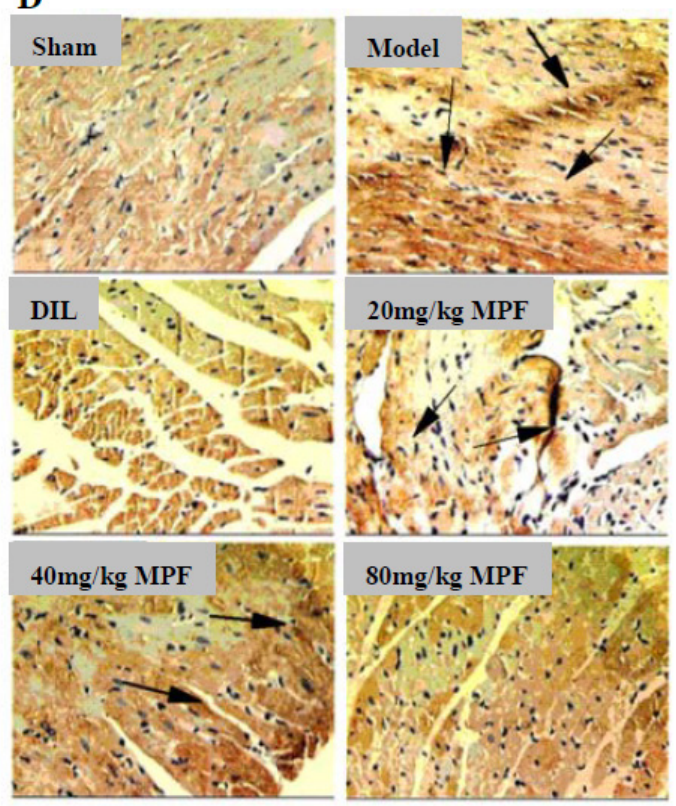

Fig. 8. (A) Effects of MPF on the expression of Bcl-2 and Bax (B) and the ratio of Bax / Bcl-2 after MI/RI in rats. The results are presented as the mean $\pm \mathrm{SD}(\mathrm{n}=8) .{ }^{\mathrm{a}} \mathrm{p}<0.05$ compared with sham control group, ${ }^{\mathrm{b}} \mathrm{p}<0.05$ compared with MI/RI model group. (C) The protein expression of Bax ( $\times 400)$, (D) the protein expression of Bcl-2 ( $\times 400)$ after MI/RI in rats. Cells were stained by immunohistochemistry and viewed under a microscope. Arrows indicate cells positive for Bax or Bcl-2 expression.

by previous findings [32]. Pretreatment with MPF significantly decreased the LDH activity in the culture medium, suggesting that its membrane stabilized activity.

ATPases play a significant role in the contraction and relaxation of cardiac muscle by maintaining normal ion levels inside myocytes. $\mathrm{Na}^{+}-\mathrm{K}^{+}$-ATPase and $\mathrm{Ca}^{2+}$-ATPase are sulfhydryl $(-\mathrm{SH})$ group-containing enzymes and are lipid dependent. A reduction in the activities of these enzymes might be due to enhanced lipid peroxidation by free radicals. Moreover, reduced activities of $\mathrm{Na}^{+}-\mathrm{K}^{+}$-ATPase and $\mathrm{Ca}^{2+}$-ATPase may be responsible for the ionic imbalance caused by myocardial ischemia [33]. As shown in Fig. 3, compared with the blank control group, the activities of $\mathrm{Na}^{+}-\mathrm{K}^{+}-\mathrm{ATPase}$ and $\mathrm{Ca}^{2+}-\mathrm{Mg}^{2+}-\mathrm{ATPase}$ were lower in the $\mathrm{H} / \mathrm{R}$ model control group. In addition, the enhanced $\mathrm{Ca}^{2+}$-ATPase activity may be due to the activation of adenylate cyclase [34]. Calcium overload in myocardial cells during ischemia activates $\mathrm{Ca}^{2+}$-dependent ATPase in the membrane, which depletes high-energy phosphate stores and thereby indirectly inhibits $\mathrm{Na}^{+}$and $\mathrm{K}^{+}$transport and inactivates $\mathrm{Na}^{+}-\mathrm{K}^{+}$-ATPase 
[35]. This process is another important factor leading to myocardial oxidative damage and apoptosis [36-38]. $\mathrm{Na}^{+}-\mathrm{K}^{+}$-ATPase maintains an active potential and myocardial excitation. In this study, we described the activating effect of MPF on ATPase and demonstrated that MPF might inhibit calcium overload by affecting ATPase activity.

We performed in vivo studies to investigate the effects of MPF on hemodynamics in MI/RI rats. In the present study, compared with the MI/RI model group, pretreatment with MPF and DIL increased HR, LVSP, $+\mathrm{dp} / \mathrm{dt}_{\text {max }}$ and $-\mathrm{dp} / \mathrm{dt}_{\text {max }^{\prime}}$ while LVDP, LVEDP and $\mathrm{t}-\mathrm{dp} / \mathrm{dt}_{\text {max }}$ were significantly decreased. These results revealed that MPF increased the ventricular compliance and cardiac diastolic function. In addition, our study indicated that MPF might have a diastolic effect on the peripheral vascular system, which contributed to a reduction in peripheral resistance, a decrease in blood pressure and rescue of cardiac afterload, as previously described [18-20]. However, further studies will be required to elucidate the detailed mechanisms underlying this phenomenon.

$\mathrm{MI} / \mathrm{RI}$ is characterized by oxidative stress and by changes in the antioxidant enzymes in the heart. There is increased production of oxygen free radicals during MI/RI, which causes unsaturated fat to undergo lipid peroxidation, thereby aggravating myocardial damage [39]. MDA, SOD and GSH-Px levels are classical indices used to evaluate tissue peroxidative injury $[40,41]$. A study in dogs has shown that IPC increases the protein expression and activity of myocardial manganese (Mn)-SOD activity not only immediately after IPC but also $24 \mathrm{~h}$ after IPC [42]. MDA, which is a lipid peroxidation end product, has been used to assess oxygen free radical-mediated injury of the I/R myocardium [43]. Our results revealed that MPF could increase the plasma SOD and GSH-Px activities and reduce the MDA content. This finding suggested that the enhancement of antioxidase activity and inhibition of peroxidation of free radicals in the myocardium might be, at least partially, involved in the cardioprotective mechanisms of MPF in response to myocardial MI/RI injury.

Additionally, we examined the mechanism of apoptosis induced by MPF by measuring Bc1-2 and Bax protein expression in myocardial tissues (44-46). Our results demonstrated that pretreatment with MPF showed no difference in the expression of Bc1-2 protein in each group but that the expression of Bax protein and the ratio of Bax to $\mathrm{Bc} 1-2$ protein were significantly decreased in the MPF pretreatment groups. These results indicate that MPF protected ischemia myocardium, largely by down-regulating the expression of Bax protein and the ratio of Bax protein to Bc1-2.

In conclusion, our study is the first attempt to investigate the cardioprotective effect and potential underlying mechanisms of MPF on myocardial ischemia. Preconditioning with MPF demonstrates a potential protective efficacy on myocardial ischemia via more than one mechanism, including inhibiting myocardial oxidative damage and cardiomyocyte apoptosis and improving heart function. Thus, further investigation of MPF as an anti-myocardial ischemia compound is warranted.

\section{Abbreviations}

MPF ( Millettia pulchra Flavonoids); MKL (Millettia pulchra (Benth.) Kurzvar. Laxior (Dunn) Z. Wei); H/R (hypoxia/ reoxygenation); MI/RI ( myocardial ischemia-reperfusion injury); LDH (lactate dehydrogenase); cNOS (constructional nitric oxide synthase); iNOS (inducible nitric oxide synthase); tNOS (total nitric oxide synthase); LAD (left anterior descending); HR (heart rate); LVSP (left ventricular systolic pressure); LVDP (left ventricular diastolic pressure); LVEDP (left ventricular end-diastolic pressure); $+\mathrm{dp}_{\mathrm{dt}} \mathrm{dmax}_{\text {(the largest }}$ upstroke velocity of the left ventricular pressure); $-\mathrm{dp} / \mathrm{dt}_{\max }$ (the largest descendent velocity of the left ventricular pressure); $\mathrm{t}-\mathrm{dp} / \mathrm{dt}_{\text {max }}$ (the interval from beginning of left ventricular contraction to $+\mathrm{dp}_{\mathrm{d}} \mathrm{dt}_{\text {max }}$ ); MDA (malondialdehyde); SOD (superoxide dismutase); GSH-Px (glutathione peroxidase); ELISA (enzyme-linked immunosorbent assay); DMEM (Dulbecco's modified Eagle's medium); FBS (fetal bovine serum); PBS (phosphate-buffered saline). 
Huang et al.: Protective Effects of MPF on Myocardial Ischemia

\section{Disclosure Statement}

The authors declare that there are no conflicts of interest.

\section{Acknowledgements}

This work was supported by the National Natural Science Foundation of China (No. 81160533, 81360129, 81460205); Guangxi Scientific Research and Technology Development Research Projects (No. 0630002-2A); Guangxi Natural Science Foundation (No. 2013GXNSFAA019175); and fund of Guangxi Key Laboratory of Functional Phytochemicals Research and Utilization (No. FPRU2013-3).

\section{References}

1 Sekikawa A, Horiuchi BY, Edmundowicz D, Ueshima H, Curb JD, Sutton-Tyrrell K, Okamura T, Kadowaki T, Kashiwagi A, Mitsunami K, Murata K, Nakamura Y, Rodriguez BL, Kuller LH: A "natural experiment" in cardiovascular epidemiology in the early 21st century. Heart 2003;89:255-257.

2 Sanada S, Komuro I, Kitakaze M: Pathophysiology of myocardial reperfusion injury: preconditioning, postconditioning, and translational aspects of protective measures. Am J Physiol-Heart C 2011;301:H1723-H1741.

-3 Lee YM, Cheng PY, Chen SY, Chung MT, Sheu JR: Wogonin suppresses arrhythmias, inflammatory responses, and apoptosis induced by myocardial ischemia/reperfusion in rats. J Cardiovasc Pharm 2011;58:133-142.

4 Chandrasekar B, Nelson JF, Colston JT, Freeman GL: Calorie restriction attenuates inflammatory responses to myocardial ischemia-reperfusion injury. Am J Physiol-Heart C 2001;280:H 2094-H2102.

5 Li C, Jackson RM: Reactive species mechanisms of cellular hypoxia-reoxygenation injury. Am J Physiol-Cell Ph 2002;282:C227-C241.

6 Burton KP, McCord JM, Ghai G: Myocardial alterations due to free-radical generation. Am J Physiol-Heart C 1984;246:H776-H783.

7 Gottlieb RA: Cell death pathways in acute ischemia/reperfusion injury. J Cardiovasc Pharm T 2011;16:233238.

8 Hori M, Nishida K: Oxidative stress and left ventricular remodelling after myocardial infarction. Cardiovasc Res 2009;81:457-464.

9 Schultz JEJ, Hsu AK, Gross GJ: Morphine mimics the cardioprotective effect of ischemic preconditioning via a glibenclamide-sensitive mechanism in the rat heart. Circ Res 1996;78:1100-1104.

10 Sato T, O’Rourke B, Marbán E: Modulation of mitochondrial ATP-dependent K+ channels by protein kinase C. Circ Res 1998;83:110-114.

11 Wang S, Dusting GJ, May CN, Woodman OL: 3', 4'-Dihydroxyflavonol reduces infarct size and injury associated with myocardial ischaemia and reperfusion in sheep. Brit J Pharmacol 2004;142:443-452.

12 Fan L, Yuan LP, Chen ZW, MA CG: Protective effect of pharmacological preconditioning of total flavone of Abelmoschl manihot on ischemical reperfusion injury myocardium in rabbits. Chin Pharm J 2005;40:836.

13 Zhang JH, Chen ZW, Wu Z: Late protective effect of pharmacological preconditioning with total flavones of rhododendra against myocardial ischemia-reperfusion injury. Can J Physiol Pharm 2008;86:131-138.

14 Dai, B: Chinese Modern Yao Medicine. Guangxi Science and Technology Publishing House, Nanning, China 2009, pp 401-405.

15 Guangxi Food and Drug Administration: Standards of Guangxi Zhuang Medicine. Guangxi Science and Technology Publishing House, Nanning, China, 2008, pp 72.

16 Jian J, Huang JC, Jao Y, Tan HD, Huang RB: Isolation and preparation of chalcone compounds from tuber of Millettia pulchra var. laxior by pre-HPLC. Chin Tradit Herb Drugs 2011;42:1313-1316.

17 Lin X, Huang ZS, Chen XY, Rong YP, Zhang SJ, Jiao Y, Huang QF, Huang RB: Protective effect of Millettia pulchra polysaccharide on cognitive impairment induced by D-galactose in mice. Carbohyd Polym 2014;101:533-543. 
Huang et al.: Protective Effects of MPF on Myocardial Ischemia

18 Zhang XD, Jiang WZ, Jiao Y, Huang RB: The Study of Longyanshen Flavonoids on Anti-lipid Peroxidation Injury Induced by Myocardial Ischemia Reperfusion in Rats. Lishizhen Med Mater Med Res 2008;19:607609.

19 Lv JH, He M, Huang JC, Lin X, Huang RB: Effect of Flavonoid of Yulangsan on ATPase and Apoptosiscorrelated Protein of Myocardial Ischemia-Reperfusion Injury. Chin J Exp Tradit Med Form 2010;16:162166.

20 Huang RB, Lv JH, Zhang XD: Effects of yulangsan flavonoids on myocardial ischemia reperfusion injury in isolated rat hearts. West China J Pharm Sci 2010;25:287-289.

21 Wang LT, Zhang B, Chen JJ: Effect of anti-fibrosis compound on collagen expression of hepatic cells in experimental liver fibrosis of rats. World J Gastroentero 2000;6:877-880.

22 Jian J, Liu X, Huang RB, Jiang WJ: Protection and its mechanism of two flavone morphons from Yulangsan on hypoxia-reoxygenation induced injury in myocardial cells. CPB 2009;7:942-945.

23 Kim KS, Takeda K, Sethi R, Pracyk JB, Tanaka K, Zhou YF, Yu ZX, Ferrans VJ, Bruder JT, Kovesdi I: Protection from reoxygenation injury by inhibition of rac1. J Clin Invest 1998;101:1821.

24 Traganos F, Darzynkiewicz Z, Sharpless T, Melamed MR: Simultaneous staining of ribonucleic and deoxyribonucleic acids in unfixed cells using acridine orange in a flow cytofluorometric system. J Histochem Cytochem 1977; 25:46-56.

25 Ono K, Matsumori A, Shioi T, Furukawa Y, Sasayama S: Enhanced expression of hepatocyte growth factor/cMet by myocardial ischemia and reperfusion in a rat model. Circulation 1997;95:2552-2558.

26 Ross Jr J: Electorcardiographic ST-segment analysis in the characterization of myocardial ischemia and infarction. Circulation 1976;53:I73-181.

27 Lorgis L, Zeller M, Dentan G, Sicard P, Richard C, Buffet P, L'Huillier I, Beer JC, Cottin Y, Rochette L,Vergely C: The free oxygen radicals test (FORT) to assess circulating oxidative stress in patients with acute myocardial infarction. Atherosclerosis 2010;213:616-621.

28 Turer AT, Hill JA: Pathogenesis of myocardial ischemia-reperfusion injury and rationale for therapy. Am J Cardiol 2010;106:360-368.

29 Lochner A, Marais E, Toit ED, Moolman J: Nitric oxide triggers classic ischemic preconditioning. Ann Ny Acad Sci 2002;962:402-414.

-30 Ghaleh B, Tissier R, Berdeaux A: Nitric oxide and myocardial ischemic preconditioning. J Soc Biologie 1999;194:137-141.

-31 Liu W, Wu S: Differential roles of nitric oxide synthases in regulation of ultraviolet B light-induced apoptosis. Nitric Oxide 2010;23:199-205.

- 32 Priscilla DH, Prince P: Cardioprotective effect of gallic acid on cardiac troponin-T, cardiac marker enzymes, lipid peroxidation products and antioxidants in experimentally induced myocardial infarction in Wistar rats. Chem-Biol Interact 2009;179:118-124.

33 Mohale DS, Dewani AP, Saoji AN, Khadse CD: Antihyperlipidemic activity of isolated constituents from the fruits of Lagenaria siceraria in albino rats. International J Green Pharm 2008;2:104.

34 Upaganlawar A, Gandhi H, Balaraman R: Effect of vitamin E alone and in combination with lycopene on biochemical and histopathological alterations in isoproterenol-induced myocardial infarction in rats. J Pharmacol Pharmacother 2010;1:24-31.

-35 Petrich ER, Schanne OF, Zumino AP: Electrophysiological responses to ischemia and reperfusion. In Myocardial Ischemia: Mechanisms, Reperfusion, Protection. Birkhäuser Basel 1996:115-133.

-36 Ganesan B, Buddhan S, Jeyakumar R, Anandan R: Protective Effect of Betaine on Changes in the Levels of Membrane-bound ATPase activity and Mineral Status in Experimentally Induced Myocardial Infarction in Wistar Rats. Biol Trace Elem Res 2009;131:278-290.

-37 Pogorelov AG, Pogorelova VN, Dubrovkin MI, Demin IP: Analysis of elemental composition (Na/K/Ca) of muscle cells in ischemia in a model of the perfused heart. Tsitologiia 2000;42:62.

38 Matsumoto T, Hisamatsu Y, Ohkusa T, Inoue N, Sato T, Suzuki S, Ikeda Y, Matsuzaki M: Sorcin interacts with sarcoplasmic reticulum $\mathrm{Ca}^{2+}$-ATPase and modulates excitation-contraction coupling in the heart. Basic Res Cardiol 2005;100:250-262.

-39 Paradies G, Petrosillo G, Pistolese M, Di Venosa N, Serena D, Ruggiero FM: Lipid peroxidation and alterations to oxidative metabolism in mitochondria isolated from rat heart subjected to ischemia and reperfusion. Free Radical Bio Med 1999;27:42-50. 
40 Wang J, Zhang QB, Jin WH, Niu XZ, Zhang H: Effects and mechanism of low molecular weight fucoidan in mitigating the peroxidative and renal damage induced by adenine. Carbohyd Polym 2011;84:417-423.

41 Tian XP, Yin YY, Li X: Effects and mechanisms of Acremoniumterricola milleretal mycelium on liver fibrosis induced by carbon tetrachloride in rats. Am J Chinese Med 2011;39:537-550.

42 Hoshida S, Kuzuya T, Fuji H, Yamashita N, Oe H, Hori M, Suzuki K, Taniguchi N, Tada M: Sublethal ischemia alters myocardial antioxidant activity in canine heart. Am J Physiol-Heart C 1993;264:H33-H39.

-43 Ozer MK, Parlakpinar H, Cigremis Y, Ucar M, Vardi N, Acet A: Ischemia-reperfusion leads to depletion of glutathione content and augmentation of malondialdehyde production in the rat heart from overproduction of oxidants: Can caffeic acid phenethyl ester (CAPE) protect the heart? Mol Cell Biochem 2005;273:169-175.

44 Portt L, Norman G, Clapp C, Greenwood M, Greenwood MT: Anti-apoptosis and cell survival: a review. BBAMol Cell Res 2011;1813:238-259.

45 Wyllie AH: "Where, 0 death, is thy sting?" A brief review of apoptosis biology. Mol Neurobiol 2010;42:4-9.

-46 Foadoddini M, Esmailidehaj M, Mehrani H, Sadraei SH, Golmanesh L, Wahhabaghai H, Valen G, Khoshbaten A: Pretreatment with hyperoxia reduces in vivo infarct size and cell death by apoptosis with an early and delayed phase of protection. Eur J Cardio-Thorac 2011;39:233-240. 